\title{
Impactos socioambientais da mineração na bacia do rio macaco no município Cachoeira do Piriá, 2008-2018.
}

Socio-environmental impacts of mining in the macaco river basin in the city of Piriá, 2008-2018.

Impactos socioambientales de la minería en la cuenca del río macaco en la Cachoeira do Piriá del municipio, 2008-2018.

Áurea Maria Da Costa Sousa Graduada, UFPA, Brasil aurea-farias@hotmail.com

Rita Denize de Oliveira Professora Doutora, UFPA, Brasil. ritadenize@ufpa.br

Jorge Sales dos Santos

Graduando, UFPA, Brasil. jorge.santos@ifch.ufpa.br 


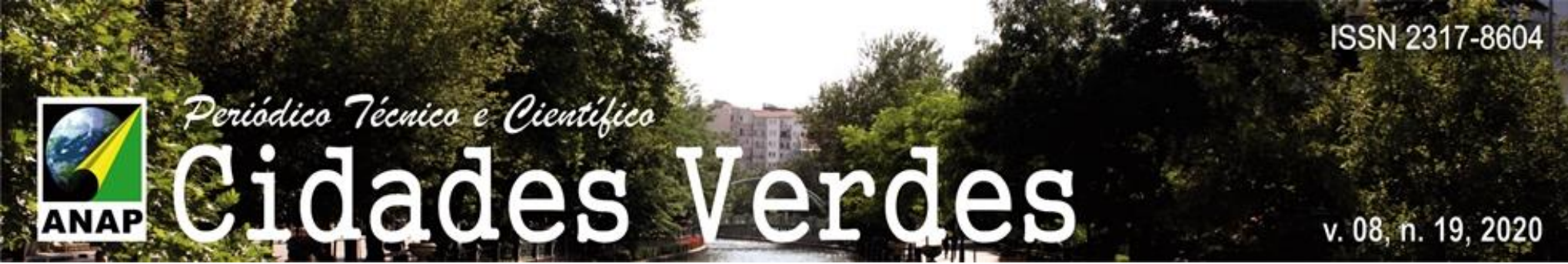

\subsubsection{Unidade de relevo}

O mapa de declividade foi gerado a partir das imagens SRTM, gerando curvas de nível com espaçamento de $5 \mathrm{~m}$ e a partir dessa informação foi gerado o modelo digital pela metodologia da Rede triangular irregular (TIN). Para a classificação de declividade das formas de relevo foi adotada a tabela da Empresa Brasileira de Pesquisa Agropecuária - Embrapa.

\begin{tabular}{|c|c|}
\hline Classes de declividade & $\begin{array}{c}\text { Declividade } \\
(\%)\end{array}$ \\
\hline Plano & $0-3$ \\
\hline Suave ondulado & $3-8$ \\
\hline Ondulado & $8-20$ \\
\hline Forte Ondulado & $20-45$ \\
\hline Montanhoso & $45-75$ \\
\hline Escarpado & $>75$ \\
\hline
\end{tabular}

Fonte: EMBRAPA, 1999.

\subsubsection{USO E COBERTURA DO SOLO}

Com o intuito de realizar a classificação do uso e cobertura do solo, para o processamento de imagens, foi utilizado o software Envi 5.4, enquanto que a análise das informações, banco de dados e layout foram processadas na plataforma ArcGIS 10.5. Para essa etapa foi utilizada duas imagens de satélite para compor a análise temporal de 10 anos, a Landsat 5 e Landsat 8, dos anos 2007 e 2017 consequentemente, da United Space in Europe, através do site da USGS, com resolução espacial de $10 \mathrm{~m}$, sistema de Coordenadas Geográficas, UTM zona $22 \mathrm{~S}$ e Datum no WGS-84.

A classificação do uso e cobertura do solo foi gerado através de um algoritmo de classificação, de Máxima Verossimilhança, na plataforma Envi 5.4. O algoritmo de Máxima Verossimilhança (MaxVer), utilizado em métodos de classificação supervisionada, consiste em coletas de amostras de treinamento na própria imagem e, a partir delas, pondera as distâncias médias dos níveis digitais das classes amostradas. Assim, estabelecidas as classes para treinamento e de acordo com a distribuição de probabilidade, o pixel que apresentar maior semelhança entre si será agrupado em uma das classes (INPE, 2002).

\subsubsection{SETORIZAÇÃO DA BACIA}

Para dividir a bacia hidrográfica foram estabelecidos primeiramente as formas de uso e ocupação do solo e da água, considerando as formas de ocupação industrial, urbana e rural no interior da bacia, levando em consideração os limites municipais e a rede de drenagem.

\section{RESULTADOS}

A bacia hidrográfica do rio Macaco, situa-se no interflúvio do rio Gurupí e Piriá, o primeiro estabelecendo limite entre o estado do Maranhão/Pará e o segundo tem como principal 


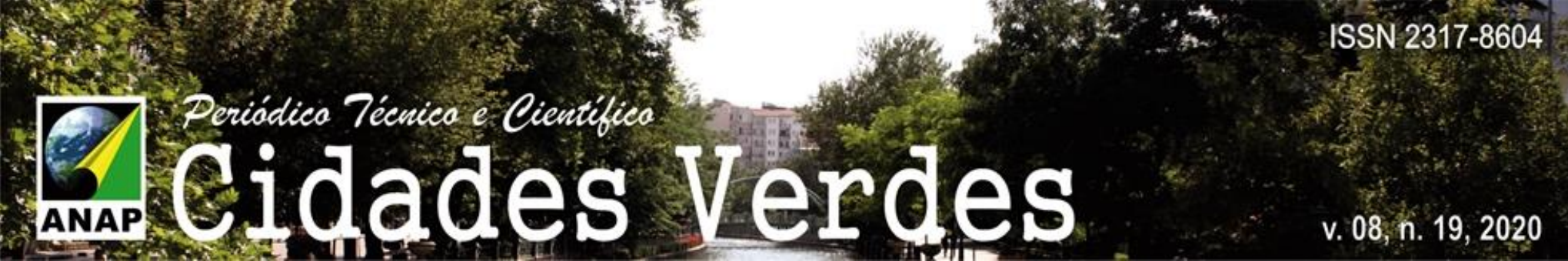

afluente o Rio Macaco, ambos com foz no oceano Atlântico. A análise da bacia hidrográfica enquanto unidade de estudo da paisagem torna-se necessário devido características especificas, pelo qual de acordo com Machado e Torres (2013, p. 46-47) deve-se considerar seus aspectos físicos, o uso do solo além de características sociais e econômicas, estabelecendo uma compreensão de sua dinâmica. A análise morfométrica da bacia utilizando parâmetros morfológicos, permite uma melhor análise seu ambiente e a sua tendência à ocorrência de eventos, como processos erosivos e inundações, assim como a incompatibilidade das ações humanas em suas formas de uso

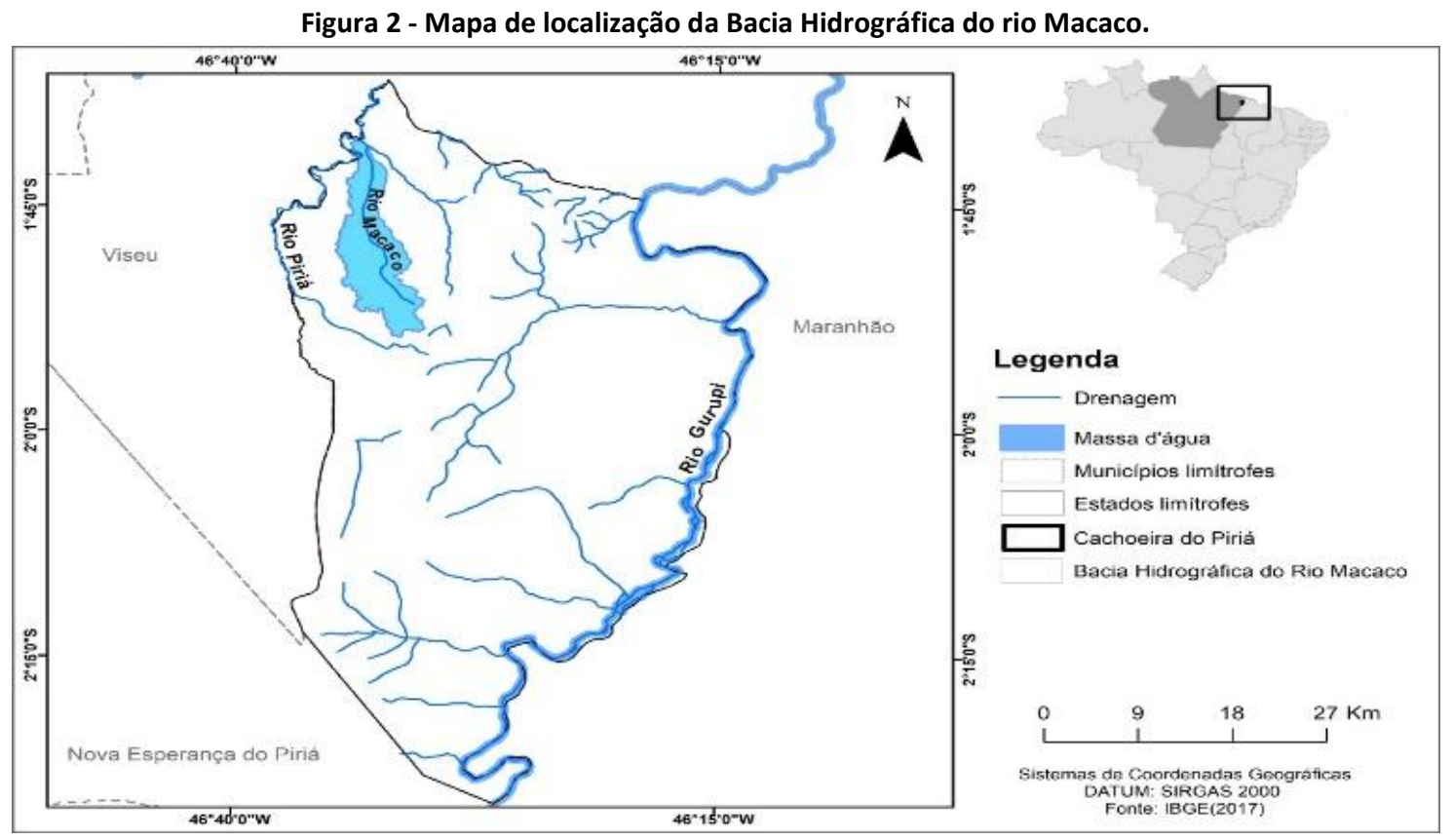

Fonte: ROCHA, 2018. 

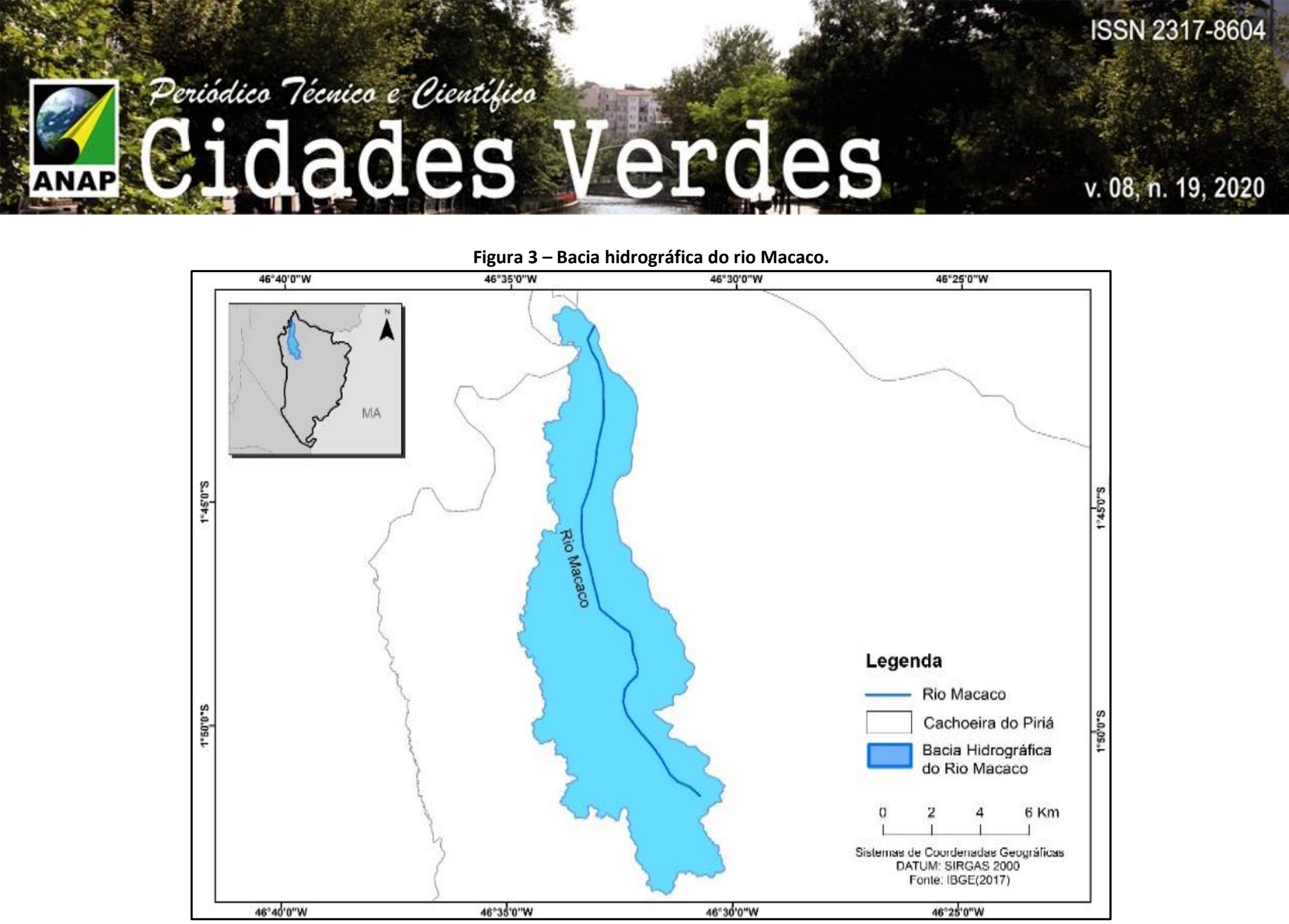

Fonte: ROCHA, 2018.

A nascente do Rio Macaco, localiza-se na comunidade Barraca da farinha e desagua no rio Piriá, na comunidade da Bela Vista, seu comprimento é de $22,16 \mathrm{~km}$, não sendo identificado possíveis afluentes em seu canal, em função da escala de análise. A área total da bacia corresponde a 94,9 $\mathrm{km}^{2}$, atravessando a área urbana em seu médio curso, suas águas possuem coloração escura, sendo classificado como Rios de Águas escuras em função do elevado teor de matéria orgânica composto por relevo plano e suave ondulado no domínio do Planalto Setentrional ParáMaranhão, que apresenta tonalidade verde escuro e verde claro, com declive variando de 0 a $3 \%$ e de $3 \%$ a $8 \%$, respectivamente e altimetria abrangendo de 12 a 39 metros no médio e baixo curso, e altimetria de 39 a 61 metros no alto curso, sendo as maiores declividades estão em alto curso e onde está instalado o núcleo urbano, com relevo fortemente ondulado. Em que predominam duas grandes unidades de solos os Plintossolos Háplicos, no médio curso característico de áreas de transição, e os Argissolos Vermelho-Amarelo, no alto curso, típico das áreas de Terra Firme. 


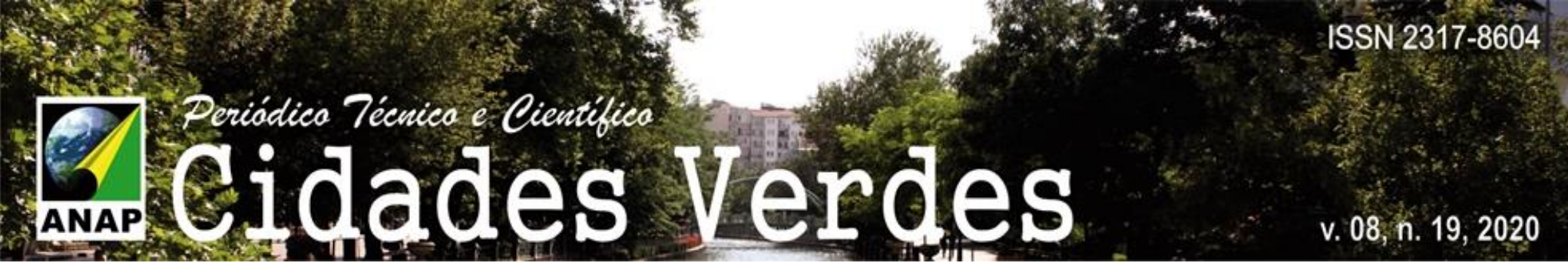

Figura 4 - Mapa de declividade da bacia hidrográfica do rio Macaco.

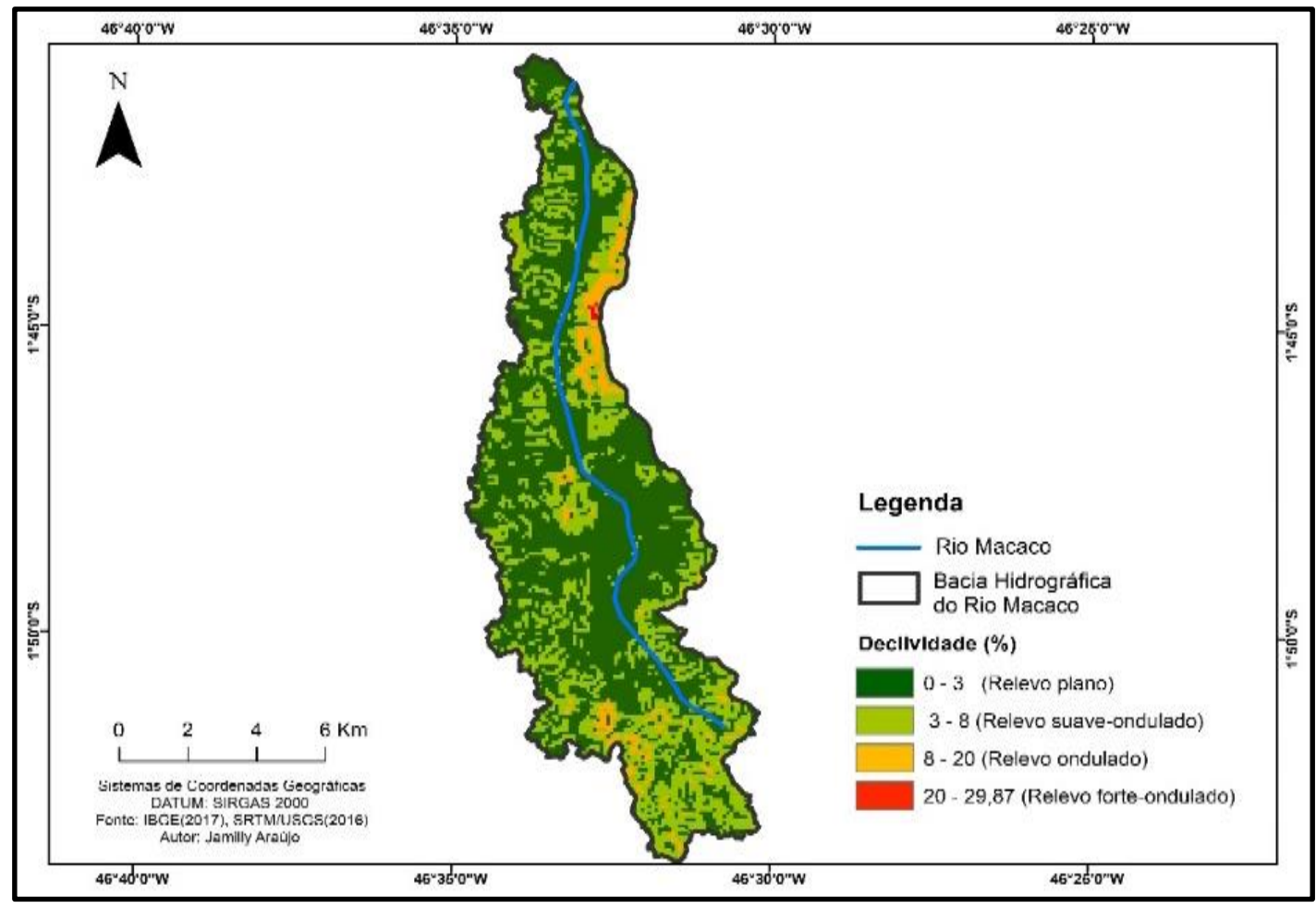

Fonte: ARAÚJO, 2018.

Figura 5: Mapa altimétrico da Bacia do Rio Macaco.

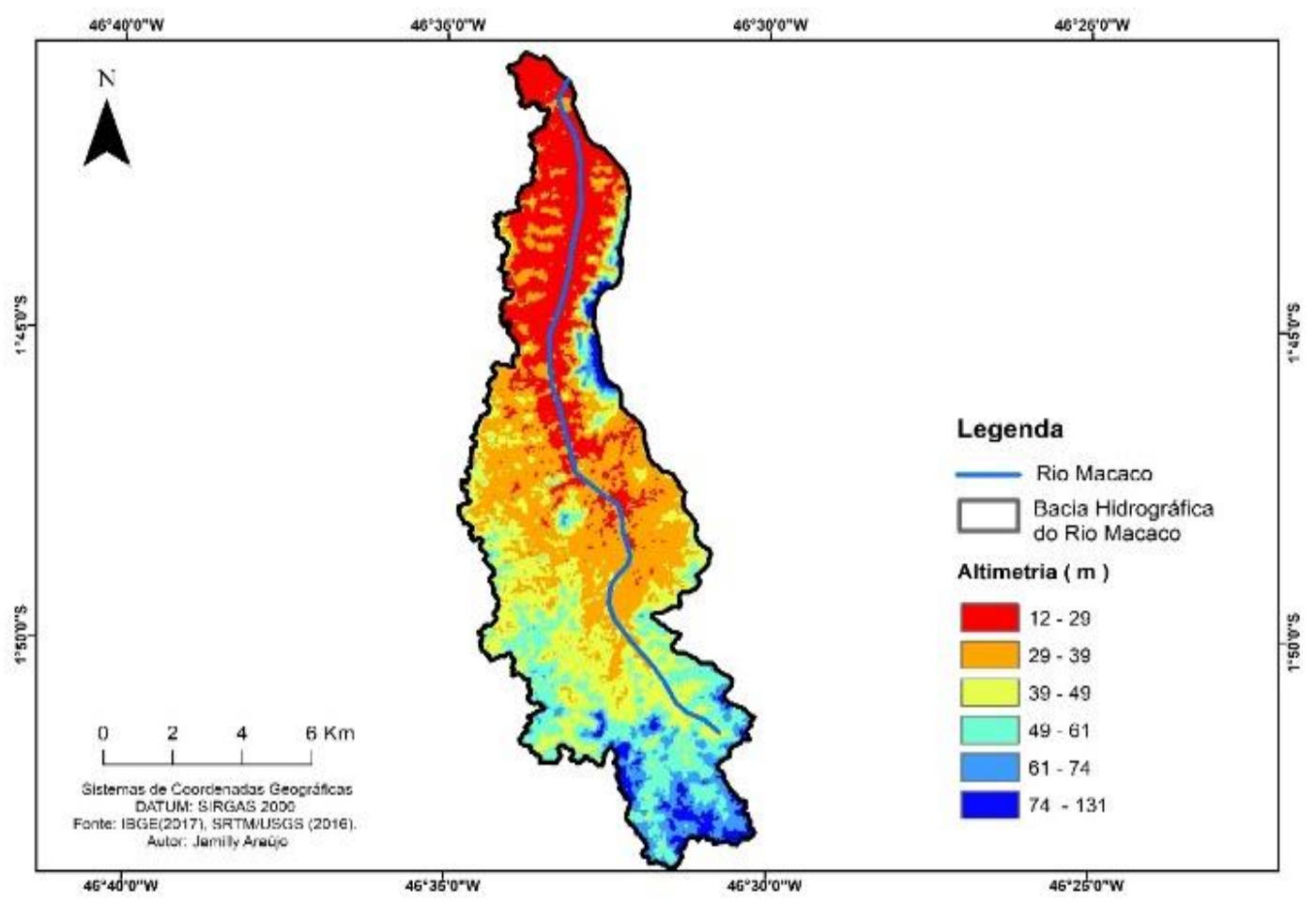

Fonte: ARAÚJO, 2018. 


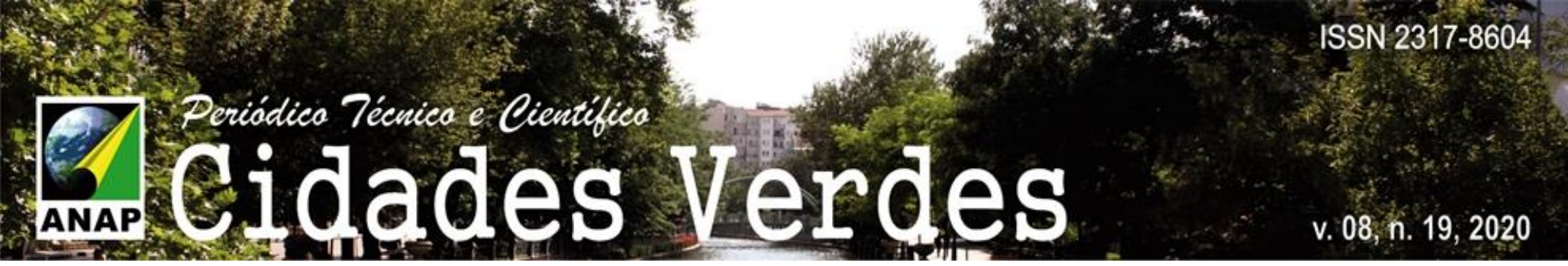

O rio Macaco, em alguns trechos na comunidade da Bela Vista, apresenta-se sem indícios de encostas fitoestáveis, ou seja, grandes partes de Florestas Ombrófilas já foram devastadas pela atividade garimpeira e para substituição de áreas para pasto, trazendo instabilidade ecológica para o regime hídrico. A drenagem do Macaco, apresenta-se, entretanto, em regime baixo em grande parte do ano, sobretudo em épocas com escassez de chuva, onde o rio perde em determinadas áreas todo o seu volume.

Em períodos úmidos, na mesma comunidade, as atividades no rio agora são destinadas à outras formas de lazer, como banhos entre jovens e crianças, além de lavagens de roupas e motocicletas pelos moradores da vila. Tricart, (1977) considera que as alterações dos sistemas ambientais, tais como as alterações do regime hídrico, assim como da superfície do solo, do efeito de intercepção da vegetação, bem como a compactação promovida pelo dos pisoteio de animais, todos esses fenômenos afetam a morfogênese, pedogênese, e regime hídrico.

O valor que ganha cada garimpeiro, depende principalmente da quantidade de outro extraído, cabendo ao garimpeiro apenas $2 \%$ do lucro, uma média de 200 a 450 reais por semana. A comercialização, segundo os garimpeiros, é feita em barra ou com o ouro bruto entre os comerciantes da cidade e com compradores de fora, pelo qual demonstram receio para adentrarem nos assuntos que diz respeito a comercialização e a integridade física dos trabalhadores. Apesar de sempre recorrentes acidentes e demais implicações na saúde dos mesmos, os casos nunca são registrados como provenientes de garimpo, pois este ainda prossegue de acordo com o comentário de alguns garimpeiros, como "único meio de manter muitas famílias".

\section{NÍVEIS DE ESTABILIDADE DOS ECOSSISTEMAS.}

Através da análise das formas de uso da paisagem, correspondente ao médio curso do rio e suas implicações na alteração do solo, relevo e cobertura vegetal, foi possível realizar através da metodologia da ecodinâmica de Tricart, a identificação da vulnerabilidade dos sistemas ambientais presentes, a partir dos critérios de estabilidades-instabilidade. Averiguando-se assim, uma dinâmica integrada à fortemente instável. Essa área de estudo correspondente ao médio curso, trecho que atravessa a área urbana, pelo qual se tem a maior concentração de garimpos, sujeitos a impactos ambientais.

Esta estabilidade ecodinamica é condicionada através da intercepção das formações vegetais, que segundo Tricart (1977, p 27, 65), desempenham um papel importante na dinâmica do ecossistema, com função estabilizadora, exercendo uma rugosidade que amortece o efeito cinético da chuva e oferece detritos vegetais ao solo, impedindo os efeitos erosivos e tornando a pedogênese mais desenvolvida. No entanto, em Cachoeira do Piriá, sobretudo nas áreas correspondentes à bacia hidrográfica foram identificadas apenas algumas faixas de mata nativa, sobretudo nas áreas correspondentes ao médio curso do rio Macaco, em sua maioria, as florestas são de ordem secundária com capoeira alta, não contribuído com o efeito fitoestável. 
